\title{
Correlates of Length of Admission among Patients Discharged in a Mono- specialist Neuropsychiatric Hospital in Nigeria
}

\author{
Onofa Lucky ${ }^{1 *}$, Sowunmi Oladipo ${ }^{1}$, Latona Opeyemi ${ }^{2}$, David Efeomo ${ }^{1}$, Ajogbon Daniel ${ }^{1}$, Awolaran \\ Busayo $^{1}$, Ighoroje Maroh ${ }^{1}$ and Majekodunmi Oluyinka ${ }^{1}$
}

${ }^{1}$ Department of Clinical Services, Neuropsychiatric Hospital Aro, Nigeria

${ }^{2}$ Department of Epidemiology \& Medical Statistics, University of Ibadan, Nigeria

Corresponding author: Dr. Onofa Lucky Umukoro, (MBBS, M.SC, FWACP) Chief Consultant Psychiatrist \& WHO Global Mental Health Scholar, Department of Clinical Services, Neuropsychiatric Hospital Aro, Nigeria, Tel: +2348033336875; E-mail: onolucky@yahoo.com

Received date: October 16, 2017; Accepted date: November 28, 2017; Published date: December 5, 2017

Copyright: (C) 2017 Lucky O, et al. This is an open-access article distributed under the terms of the Creative Commons Attribution License, which permits unrestricted use, distribution, and reproduction in any medium, provided the original author and source are credited.

Citation: Onofa L, Sowunmi O, Latona O, David E, Ajogon D, et al. (2017) Correlates of Length of Admission among Patients Discharged in a Monospecialist Neuropsychiatric Hospital in Nigeria. Clin Psychiatry, Vol.3 No.3:17.

\section{Abstract}

Introduction: The concept of length of admission among psychiatric patients may be used as an indicator of service efficiency, quality of care and also for planning and distribution of hospital resources. Most studies on length of stay among psychiatric patients in Nigeria were conducted in Psychiatry department of tertiary hospitals with rarity of such studies in psychiatric mono-specialist where we have bulk of in-patients.

Aim: This study was undertaken to determine the factors that influence length of admission among patients discharged in a specialist Neuropsychiatric Hospital in Nigeria.

Methodology: This was a descriptive retrospective study at the Neuropsychiatric Hospital Aro Abeokuta Ogun State Nigeria. Valid Case notes of 605 patients admitted into the hospital and discharged in 2013(January-December) were reviewed. Data was analysed using SPSS version 21.

Results: There were 605 patients with 642 admissions. The majority of the patients were males (59.7\%) and mean(SD) age of the sample was $36.3(19.0)$ years. The median duration of admission was 61.0 days. The factors that significantly $(P<0.05)$ prolonged admission beyond 30 days were; single marital status, unemployment, past psychiatric history, duration of untreated psychosis $>6$ months, diagnoses of schizophrenia, bipolar affective disorders, schizoaffective disorder and behavioural disorder due to psychoactive use, use of long acting depot preparation, poly-therapy treatment, multiple episodes of illness and admission, and the request of specialised laboratory investigations. Logistic regression analysis showed that independent predictors of prolonged length of stay were duration of untreated psychosis $>6$ months, a past psychiatric history, diagnosis of bipolar affective disorder, poly-therapy treatment and the request of specialized laboratory investigations.
Conclusion: Our study has shown the importance of socioeconomic and clinical factors on LOS and the need for mental health professionals to be familiar with those factors while planning and delivering psychiatric treatment. It is hoped that this study will provide a template that policy makers and the government as a whole can use to improve mental health service in Nigeria.

\section{Keyword:}

Length of stay; Mono-specialist psychiatric hospital; Correlates of hospital stay; Nigeria

\section{Introduction}

The concept of length of admission among psychiatric patients may be used as an indicator of service efficiency, quality of care and also for planning and distribution of hospital resources [1,2]. Psychiatric facilities have a duty of maintaining a high level of quality care while meeting the challenges of reducing the cost of care [3].

Prolonged admission poses greater financial and economic burden on careers, continuously isolates the patient from their social network and may initiate maladaptive behavioural patterns in patients [4]. Factors influencing length of admission for psychiatric patients include variables like clinical diagnoses, co-morbidities, treatment modalities and socio-demographic factors as age, level of social support and global functioning $[3,5-7]$.

There are no accepted guidelines of length of admission for psychiatric in-patients [6]. However some studies found an average of 28 days of in-patient care among psychiatric patients in the general hospital setting and this duration was considered adequate $[3,8]$. One study reported that patients with the diagnosis of schizophrenia may require over 30 days on admission [9]. 
In the last few decades, Western countries went through a process of deinstitutionalization of psychiatric care. Attention has drifted from more in-patient treatment to in the community. Nowadays, longer hospital stay may imply poor mental health care and support in the community. Reduction of length of admission has been associated with less expenditure and successful treatment in the community [4].

In Nigeria, psychiatric treatment remains largely institution based. Although the Nigerian Federal Health Ministry adopted mental health as a component of primary health care in 1989 this is yet to be integrated fully into primary health care services [10]. In recent time, there are efforts to integrate mental health into primary health care in some states of the country [11]. Given the inadequate community psychiatric care coverage in Nigeria, majority of the patients receive hospital based treatment.

It will be difficult to completely replace hospital based care because some patients will continue to have need for acute and specialised in-patient care. Since the effects of institutionalization and social rehabilitation are directly related to the length of in-patient admission, the length of stay has become an issue when discussing patient care in psychiatric facilities.

Research on length of stay of psychiatric in-patients remains largely under-investigated. Few studies on length of stay on admission among psychiatric patients in Nigeria were carried out in psychiatric departments of teaching hospital setting $[3,7,11,12]$. However, there is scarcity of study on length of stay among psychiatric patients admitted to mono-specialist psychiatric hospitals in Nigeria.

The study aims to determine the clinical, treatment and sociodemographic variables that influences the length of admission among inpatients in a specialist Neuropsychiatric Hospital in Nigeria. Some of these variables may be modified through changes in clinical practice and service delivery. It is hoped that the findings of this study will be useful to physicians and other health care givers in the field of psychiatry who are involved in patient care.

\section{Methodology}

\section{Study site}

The study centre was Federal Neuropsychiatric Hospital, Aro, Abeokuta, Ogun State, Nigeria. The hospital was established in 1954 and has a total bed capacity of 546 for inpatient care. The hospital plays a strategic role in mental health care for patients from all parts of Nigeria and neighbouring countries [13].

\section{Study design and sample size}

This was a descriptive retrospective review of case files of all 632 patients admitted and discharged from the hospital in 2013 (January-December). However, 605 cases who received definitive psychiatric diagnosis, based on the International Classification of Diseases (ICD-10) were included in the study.
The mean length of admission was estimated for patients with more than 1 admission during the 12 months study period.

\section{Data collection and analysis}

The case records of patients discharged was retrieved from the medical records unit of the hospital. A semi-structured preform designed by the authors was used to extract the following information from the case files: socio-demographic variables, clinical diagnosis, co-morbidity, treatment variables and outcomes at discharge.

Data analysis was done using Statistical Package for Social Sciences (SPSS) version 21. Descriptive statistics was used to describe the socio-demographic, clinical and treatment characteristics of the patients. Chi-square statistics was used to test association between categorical variables. The length of admission was dichotomized into 2: short stay ( $\leq 30$ days) and long stay (>30 days). Multiple logistic regression was used to explore the relationship between predictor variables and length of stay. P-value of significance was set at $<0.05$.

\section{Ethical Consideration}

Approval was obtained from the Research and Ethical Committee of Neuropsychiatric Hospital, Aro. All information retrieved from patients' case files were treated with confidentiality. Patient's names and hospital numbers were not used at any stage of the study.

\section{Result}

\section{Socio-demographic profile}

Out of the 632 patients discharged in 2013, 605(95.7\%) patients had valid case notes for analysis. The mean (SD) age was 36.3(18.0) years. The majority of respondents were males (59.7\%), young adults (56.2\%), had completed secondary level of education (39.8\%), had never been married (63.3\%), and were unemployed (58.5\%) (Table 1 ).

Table 1 Socio-demographic profile and clinical variables of patients.

\begin{tabular}{|l|l|l|}
\hline \multicolumn{2}{|l|}{ Variables } & $\mathbf{n}$ \\
\hline Sex & 361 & 59.7 \\
\hline Male & 244 & 40.3 \\
\hline Female & \multicolumn{2}{|l|}{} \\
\hline Age(Years) & 340 & 56.2 \\
\hline $18-39$ (young adulthood) & 208 & 34.4 \\
\hline $40-59$ (middle adulthood) & 57 & 9.4 \\
\hline$\geq 60$ (late adulthood) & & 63.3 \\
\hline Marital Status & 383 & 25.1 \\
\hline Single (never married) & 152 & \\
\hline Married &
\end{tabular}




\begin{tabular}{|c|c|c|}
\hline$* 1 \mathrm{~S} / \mathrm{D} / \mathrm{W}$ & 70 & 11.6 \\
\hline \multicolumn{3}{|l|}{ Educational Level } \\
\hline No formal education & 50 & 8.3 \\
\hline Primary & 98 & 16.2 \\
\hline Secondary & 241 & 39.8 \\
\hline *2Tertiary & 216 & 35.7 \\
\hline \multicolumn{3}{|l|}{ Employment Status } \\
\hline Employed & 227 & 37.5 \\
\hline Retired/student & 24 & 4 \\
\hline Unemployed & 354 & 58.5 \\
\hline \multicolumn{3}{|c|}{ Duration of Admission (in days) } \\
\hline Short Stay $(\leq 30)$ & 304 & 50.2 \\
\hline Long Stay $(\geq 30)$ & 301 & 49.8 \\
\hline \multicolumn{3}{|c|}{ Duration of untreated mental illness } \\
\hline$<6$ months & 278 & 46 \\
\hline $6-24$ months & 195 & 32.2 \\
\hline$>24$ months & 132 & 21.8 \\
\hline \multicolumn{3}{|l|}{ Past Psychiatric History } \\
\hline Yes & 345 & 57 \\
\hline No & 260 & 43 \\
\hline \multicolumn{3}{|l|}{ Diagnosis } \\
\hline *3Schizophrenia & 377 & 62.3 \\
\hline Depressive Disorder & 35 & 5.8 \\
\hline Bipolar Affective Disorder & 91 & 15 \\
\hline *4MBD & 148 & 24.4 \\
\hline *5Others & 37 & 6.1 \\
\hline \multicolumn{3}{|c|}{ Number of Admissions (lifetime) } \\
\hline 1 admission & 409 & 67.6 \\
\hline 2 admissions & 127 & 21 \\
\hline$\geq 3$ admissions & 69 & 11.4 \\
\hline \multicolumn{3}{|l|}{ Medical Co-morbidity } \\
\hline Hypertension & 48 & 7.8 \\
\hline Others & 31 & 5.1 \\
\hline \multicolumn{3}{|c|}{ *1 (Separated, Divorced, or Widowed) } \\
\hline \multicolumn{3}{|c|}{ *2 (Post-secondary, University, or other forms of Higher Education) } \\
\hline \multicolumn{3}{|c|}{ *3 (includes Schizoaffective disorders and Delusional disorders) } \\
\hline \multicolumn{3}{|c|}{ *4 (Mental and Behavioral Disorders due to use of Psychoactive Substances) } \\
\hline \multicolumn{3}{|c|}{ *5 (includes Dementia, Epilepsy, Learning Disability and Personality disorders) } \\
\hline $\begin{array}{l}{ }^{* 6} \text { (includes Diabetes } \\
\text { disorders, Eye disorders }\end{array}$ & IAIDs, & is, Respiratory \\
\hline
\end{tabular}

\section{Clinical variables of respondents}

The median duration of admission was 61.0 days. A significant proportion of patient spent 30 days or less on admission (50.2\%), had a previous psychiatric history $(57.0 \%)$ and had up to 6 months duration of untreated mental illness (46.0\%). The most frequently diagnosed disorder was Schizophrenia (59.7\%). This was followed by Mental and Behavioural Disorders due to use of psychoactive substances (14.5\%). Hypertension was the commonest medical co-morbidity. Almost all patients (98\%) had baseline investigation results (i.e. full blood count, electrolytes/ urea/creatinine and urinalysis).

Table 2 Treatment and outcome variables of the patients.

\begin{tabular}{|c|c|c|}
\hline Variables & $\mathbf{N}$ & $\%$ \\
\hline \multicolumn{3}{|l|}{ Laboratory Investigations } \\
\hline *1 Baseline/Routine Investigations & 593 & 98 \\
\hline Urine Toxicology & 157 & 25.9 \\
\hline *2 Specialized Investigations & 98 & 16.2 \\
\hline \multicolumn{3}{|l|}{ Psychotrophics } \\
\hline *3Antipsychotics & 558 & 92.2 \\
\hline *4Antidepressants & 63 & 10.4 \\
\hline *5 Mood Stabilizers & 118 & 19.5 \\
\hline *6 Depot preparations & 122 & 42.1 \\
\hline Electroconvulsive Therapy & 9 & 1.5 \\
\hline * 7 Polytherapy & 345 & 57 \\
\hline \multicolumn{3}{|l|}{ Outcome at Discharge } \\
\hline Absconded/DAMA ${ }^{\star} 8 /$ Referred/Worsened/Died & 58 & 96 \\
\hline Stable Mental State & 547 & 90.4 \\
\hline \multicolumn{3}{|c|}{ *1 (Full blood count, electrolytes/urea/creatinine, urinalysis) } \\
\hline \multicolumn{3}{|c|}{$\begin{array}{l}* 2 \text { (x-rays, CT scans, renal and liver function test, electroencephalogram, thyroid } \\
\text { function tests etc.) }\end{array}$} \\
\hline \multicolumn{3}{|c|}{ *3 (typical and atypical antipsychotics including clozapine). } \\
\hline \multicolumn{3}{|c|}{ *4 (tricyclic antidepressants and selective serotonin reuptake inhibitors). } \\
\hline \multicolumn{3}{|l|}{ *5 (carbamazepine, sodium valproate and lithium). } \\
\hline \multicolumn{3}{|c|}{$\begin{array}{l}\text { *6 (fluphenazine, flupenthixol and zuclopenthixol decanoate, including risperdal } \\
\text { costa). }\end{array}$} \\
\hline \multicolumn{3}{|c|}{$\begin{array}{l}\text { *7 (a combination of any of medication, psychological, social, nutritional or } \\
\text { occupational therapy). }\end{array}$} \\
\hline
\end{tabular}

\section{Physical treatment and outcome}

Most of the participants were on antipsychotic medications (92.2\%). Almost $50 \%$ of the patients were on intramuscular depot injections while $57 \%$ had poly-therapy (a combination of any of pharmacological, psychological, social, occupational therapy). ECT was administered to only $1.5 \%$ of the sample. At the time of discharge from inpatient care, $90.2 \%$ had improved and were considered stable (Table 2 ). 
Association between socio-demographic, clinical, treatment and outcome variables and length of stay

The socio-demographic variables that were significantly influenced the of length stay were: single marital status $(\chi 2=17.995 ; p=0.001)$, employment status $(\chi 2=12.377 ; p=0.002)$, past psychiatric history $(\chi 2=10.107 ; p=0.001)$, duration of untreated psychosis $>6$ months, $(\chi 2=22.939 ; p<0.001)$, having diagnoses of schizophrenia, bipolar affective disorder, and mental and behavioural disorder due to psychoactive substance use $(P<0.05)$, Urine drug screening and other special investigations (e.g. retroviral disease screening, chest $x$-ray, thyroid function tests and renal function tests and electroencephalogram), when requested for patients, were noted to be significantly influenced length of stay $(P<0.05)$. The treatment and outcome variables observed to be significantly associated with length of stay were the use of depot preparation $(\chi 2=14.294 ; \quad p<0.001)$, poly-therapy treatment $(\chi 2=8.128$; $p=0.004)$ and multiple number of admission $(\chi 2=8.167 ; p=0.017)$ Among the schizophrenic spectrum disorders (schizophrenia, schizoaffective and delusional disorders), it was only schizophrenia that had significant association with the length of stay. The category classified as others include dementia, epilepsy, learning disability and personality disorders had no significant association with the duration of stay (Table $\mathbf{3}$ ).

Table 3 Variables that show significant association with duration of stay (in days).

\begin{tabular}{|c|c|c|c|c|}
\hline Variables & $\begin{array}{l}\text { short stay } \\
\text { (<30 days) }\end{array}$ & Long stay (>30 days) & $x^{2}$ & $\mathbf{P}$ \\
\hline \multicolumn{5}{|l|}{ Marital Status } \\
\hline Single (Never Married) & $173(45.2 \%)$ & $210(54.8 \%)$ & 17.995 & $<0.001$ \\
\hline Married & $99(65.1 \%)$ & $53(34.9 \%)$ & & \\
\hline S/D/W & $35(45.7 \%)$ & $38(54.3 \%)$ & & \\
\hline \multicolumn{5}{|l|}{ Employment Status } \\
\hline Employed & Employed & $92(40.5 \%)$ & 12.377 & 0.002 \\
\hline Retired/Student & $11(45.8 \%)$ & $13(54.2 \%)$ & & \\
\hline Unemployed & $158(44.6 \%)$ & $196(55.4 \%)$ & & \\
\hline \multicolumn{5}{|l|}{ Past Psychiatric History } \\
\hline Positive & $154(44.6 \%)$ & $191(55.4 \%)$ & 10.107 & 0.001 \\
\hline Negative & $150(57.7 \%)$ & $110(42.3 \%)$ & & \\
\hline \multicolumn{5}{|c|}{ Duration of Untreated Mental IIIness } \\
\hline$<6$ months & $154(55.4 \%)$ & $124(44.6 \%)$ & 22.939 & $<0.001$ \\
\hline 6-24 months & $108(55.4 \%)$ & $87(44.6 \%)$ & & \\
\hline$>24$ months & $42(31.8 \%)$ & $90(68.2 \%)$ & & \\
\hline \multicolumn{5}{|l|}{ Schizophrenia } \\
\hline Positive & $170(45.1 \%)$ & $207(54.9 \%)$ & 10.634 & 0.001 \\
\hline Negative & $134(58.8 \%)$ & $94(41.2 \%)$ & & \\
\hline \multicolumn{5}{|c|}{ Bipolar Affective Disorder } \\
\hline Positive & $59(64.8 \%)$ & $32(35.2 \%)$ & 9.117 & 0.003 \\
\hline Negative & $247(47.7 \%)$ & $269(52.3 \%)$ & & \\
\hline \multicolumn{5}{|c|}{ Mental and Behavior Disorder due to psychoactive substance use } \\
\hline Positive & $62(41.9 \%)$ & $86(58.1 \%)$ & 5.472 & 0.019 \\
\hline Negative & $242(53.0 \%)$ & $269(49.2 \%)$ & & \\
\hline \multicolumn{5}{|l|}{ Urine Toxicology } \\
\hline Yes & $67(32.7 \%)$ & $90(57.3 \%)$ & 4.864 & 0.027 \\
\hline No & 237 (52.9\%) & $211(47.1 \%)$ & & \\
\hline
\end{tabular}


Logistic regression analysis showing independent correlates of length of stay (in days)

Table 4 Binary logistic regression relating length of stay to predictor variables

\begin{tabular}{|c|c|c|c|c|c|c|}
\hline Variables & $\operatorname{Exp}(B)$ & Wald & Df & $p$-value & $95 \% \mathrm{CL}$ & Reference \\
\hline Marital Status & 8.323 & & 2 & 0.016 & & \\
\hline Single & 1.09 & 0.088 & 1 & 0.766 & $0.618-1.921$ & $\mathrm{~S} / \mathrm{D} / \mathrm{W}$ \\
\hline Married & 0.576 & 2.978 & 1 & 0.084 & $0.308-1.078$ & \\
\hline Employment Status & & 2.709 & 2 & 0.258 & & Unemployed \\
\hline Employed & 0.741 & 2.453 & 1 & 0.117 & $0.509-1.078$ & \\
\hline Retired/Student & 1.114 & 0.049 & 1 & 0.826 & $0.427-2.905$ & \\
\hline Duration of Untreated IIIness & & 14.883 & 2 & 0.001 & & $>24$ months \\
\hline$<6$ months & 0.474 & 9.185 & 1 & 0.002 & $0.293-0.768$ & \\
\hline 6-24 months & 0.377 & 14.416 & 1 & $<0.001$ & $0.228-0.624$ & \\
\hline Past Psych History & 0.66 & 4.076 & 1 & 0.043 & $0.441-0.998$ & \\
\hline Schizophrenia & 0.831 & 0.662 & 1 & 0.416 & $0.531-1.299$ & \\
\hline Bipolar Disorder & 1.843 & 3.964 & 1 & 0.046 & $1.010-3.365$ & \\
\hline MBD & 0.857 & 0.266 & 1 & 0.606 & $0.477-1.540$ & \\
\hline Urine Toxicology & 0.954 & 0.022 & 1 & 0.881 & $0.541-1.693$ & \\
\hline Specialized Tests & 0.489 & 8.139 & 1 & 0.004 & $0.229-0.800$ & \\
\hline Depot preparations & 0.747 & 1.961 & 1 & 0.161 & $0.497-1.124$ & \\
\hline Poly-therapy & 0.578 & 7.397 & 1 & 0.007 & $0.389-0.858$ & \\
\hline $\begin{array}{l}\text { Number } \\
\text { (Lifetime) }\end{array}$ of $\quad$ Admission & & 1.721 & 2 & 0.423 & & $\geq 3$ \\
\hline 1 admission & 0.675 & 1.66 & 1 & 0.198 & $0.371-1.228$ & \\
\hline 2 admissions & 0.697 & 1.204 & 1 & 0.272 & $0.366-1.328$ & \\
\hline Constant & 11.396 & 44.233 & 1 & 0.001 & & \\
\hline \multicolumn{7}{|l|}{${ }^{*} \mathrm{p}$ is significant when $<0.05$} \\
\hline \multicolumn{7}{|l|}{$\operatorname{Exp}(B)=$ Odds Ratio } \\
\hline \multicolumn{7}{|l|}{$\mathrm{CL}=$ Confidence Interval } \\
\hline $\mathrm{Df}=$ degree of Freedom & & & & & & \\
\hline
\end{tabular}

Table 4 shows the multivariate analysis of independent correlates of length of stay (in days). A test of the full model against a constant only model was statistically significant, indicating that the predictors as a set reliably distinguished between short and long stay $(\chi 2=87.483 ; p<0.001 ; d f=16)$. Nagelkerke's R2 of 0.178 indicated a mildly strong relationship between prediction and groupings. Prediction success overall was $63.6 \%$ (63.8\% for short stay and $63.5 \%$ for long stay. The Wald test statistics demonstrated that the duration of untreated mental illness, a past psychiatric history, a diagnosis of bipolar affective disorder, the request of specialised investigations and the use of poly-therapy made the most significant contribution to prediction. Exp (B) value indicated that when a diagnosis of bipolar affective disorder was made, the likelihood of long stay on admission was decreased by an approximate factor of 2 .

\section{Discussion}

The current study retrospectively reviewed inpatient admission records from a mono-specialist psychiatric hospital in a low resource setting over a 12 months period. The focus was on length of stay (LOS) and its association with patient's sociodemographic, clinical, treatment and outcome variables.

We found that married patients significantly had a shorter LOS, a finding that is similar to a previous study done in a tertiary setting in Ilorin, Kwara State, Nigeria [7]. The association between marital status and LOS have been opined to be related 
to the positive impact of social support, which provides selfexpression and practical feedback from significant others about problems experienced. Marriage could have provided motivation, encouragement to achieve goals, assistance in drug monitoring and avenue for fun sharing with relaxation. Thus a dysfunctional social network may be associated with increased severity of symptoms which may lead to prolonged LOS. In addition, the increased interest shown by significant relatives is likely to be associated with early detection and presentation of patients which may have contributed to the short LOS observed in this study.

Furthermore, respondents who were employed showed a significant association with a shorter LOS, a finding that opposed earlier finding done in Nigeria [7]. This was however similar to what was observed in another previous study in Nigeria [12]. The presence of significant association between employment status and LOS give credence to reports that the pattern of LOS is a reflection of the style of practice of the psychiatrist and the hospital policies in the facility of care [12]. The choice of medication, dose range, use of poly-therapy and the hospital policy on the duration for observation when acute symptoms have resolved are key factors that will influence the LOS. Monospecialist hospitals unlike teaching hospital settings are more flexible, have more space for in-patients facility and less turnover rate which is likely to influence the LOS.

The presence of a past psychiatric history and duration of untreated mental illness were both observed in our study to be associated with a longer LOS. This was in tandem with previous studies on LOS [14-17]. These variables are often associated with a worsening symptom severity $[16,17]$. Multiple episodes and long duration of untreated illness are usually associated with poor response to medication which may be related to the illness process, poor compliance or development of resistance to medications initially used to manage the illness [14,15].

In this study it was observed that a diagnosis of schizophrenia and mental and behavioural disorder due to psychoactive substance use were significantly associated with longer LOS. This is similar to previous studies $[7,14-18]$ which also observed that these disorders were associated with a longer hospital stay. Master et al explained that this group of disorders are chronic and debilitating, often requiring a longer time for resolution of symptoms and special forms of treatment such as drug dependence treatment and rehabilitation in therapeutic communities [14]. However, we found that the diagnosis of bipolar affective disorder was associated with shorter duration of hospital stay. This finding is in contrast with previous studies $[4,12,16]$. While the explanation for this finding may not be known in the immediate, we theorized that time of onset of overt manic symptoms to presentation and admission in the hospital may be of shorter duration compared to Schizophrenia and Substance use disorders. In addition, bipolar symptoms may resolve more quickly upon commencement of medications.

It was noted that patients who had specialised investigations such as drug toxicology, HIV screening and chest X-ray had a longer LOS. This finding is in keeping with the review done by Kirshner [8]. These investigations are usually requested to rule out a co-morbid psychoactive drug problem or a general medical condition. Co-morbidity in whatever form is usually seen to worsen symptoms severity in addition to predisposing respondents to treatment resistance [19].

The use of depot medication was observed to be associated long LOS. This is in keeping with previous studies [7,8,16-18]. The common depot preparation (fluphenazine decanoate and flupenthixol decanoate) used in the study centre are 1st generation antipsychotics which may be associated with extrapyramidal side effects in addition to other possible motor disorders [19,20]. Moreover depot medication is usually indicated for poor compliance with medication and/or poor response to treatment [12]. The use of more than one antipsychotic may be associated with treatment resistance or increased manifestation of side effective of the individual antipsychotic. These factors may extend the time spent on admission and thus contribute to a longer LOS in patients.

The management of patients at the study site is multidisciplinary. However, some of the patient may require other (psychological therapy, social works therapy, occupational therapy, physical therapy and nutritional therapy) extensive therapy in addition to pharmacological therapy which they all receive. Poly-therapy in most poor resource facilities is usually associated with a longer time if detailed information that will optimize treatment will be required.

Multivariate analysis showed that duration of untreated psychosis, past psychiatric history, carrying out special laboratory investigations and receiving poly-therapy were the most significant positive predictors of long LOS. These variables mentioned above are usually related to disease chronicity and severity. Masters et al believed that the dramatic physical toll that severe mental illness also takes on these patients is a possible explanation for the predictive powers of these variables [14].

\section{Study Limitation}

Our study has certain limitations which must be addressed and may point to directions for further studies. The lack of quantitative ratings of symptomatic illness-severity as well as sampling patients in a single institution makes the findings not necessarily generalizable to other hospital settings like the teaching hospitals in Nigeria. We also should reiterate that these findings are from psychiatric units specifically targeted at a population of severely mentally ill patients with major psychotic or mood disorders. The study, being a retrospective study gives the likely possibility that some of the information about patients may have been lost and thus influence the finding of this study. The study considered all patients admitted and discharged within 12 months calendar year in 2013 without thorough evaluations of variables influencing short length of stay. It is however recommended that future research should address the econometrics of short length of stay. Among the group for long and short stay patients they received polytherapy which comprises psychotropic medications, psychosocial therapy, nutritional and occupational therapy. The specific psychosocial intervention was not provided. 
In spite of this, this study has some remarkable strengths such as providing important information on socio-demographic, clinical, medical co-morbidity and treatment variables.

\section{Conclusion}

Our study has shown the import of socioeconomic factors on LOS and the need to de-stigmatize mental illness so that our patients can have access to jobs which will increase the economic status and improve the chances of marriage and access to a confiding partner. There is a need to improve on the current preventive measure on mental disorder. This is likely to improve on the pathway to care. It is important that psychiatrists should be familiar with factors that are associated with LOS while planning and delivering psychiatric treatment. Finally, it is hoped that this study will provide a template that policy makers and the government as a whole can use to improve mental health services in Nigeria.

\section{References}

1. Lezzoni L (1996) Risk Adjustment for Measuring Health Care Outcomes. Ann Epidemiol 6: 365-366.

2. Jiménez RE, Lam RM, Marot M, Delgado A (2004) Observedpredicted length of stay for an acute psychiatric department, as an indicator of inpatient care inefficiencies. Retrospective case-series study. BMC Health Serv Res 10: 1-10.

3. Mezzich EJ, Coffman MS (1985) Factors Length Influencing of Hospital. Hosp Community Psychiatry 36: 1262-1270.

4. Douzenis A, Seretis D, Nika S, Nikolaidou P, Papadopoulou A, et al. (2012) Factors affecting hospital stay in psychiatric patients: the role of active comorbidity. BMC Health Serv Res 12: 166.

5. Talabi OA (2003) A 3-year review of neurologic admissions in University College Hospital Ibadan, Nigeria. West Afr J Med 22: 150-151.

6. Robert LT, McLay N, Amado L, Hammer MC (2005) Predictors of Lenght of Stay in a Psychiatric Ward Serving Active Duty Military and Civilian Patients. Mil Med 170: 4-7.

7. Adegunloye OA, Yussuf AD, Ajiboye PO, Issa BA, Buhari OIN (2009) Correlates of Lenght of Tay among Psychiatirc In-Patients in a Tertiary Health Institution in Nigeria. Res J Med Sci 3: 56-61.

8. Kirshner LA (1982) Lenght of Stay Of Psychiatric Patients: A Critical Review and Discussion. J Nerv Ment Dis 170: 27-33.
9. Kovach L (1991) Power and Governance Issues in General Hospital Psychiatry. Hosp (Lond 1886) 42: 1169-1172.

10. Gureje O, Lasebikan Vo (2006) Use of mental health services in a developing country Results from the Nigerian survey of mental health and well-being. Soc Psychiatry Psychiatr Epidemiol 41: 44-49.

11. Adebowale $T$, Umukoro Lucky $\mathrm{O}$, Gater R, Akinhanmi A, Ogunlesi A, et al. (2014) Evaluation of a mental health training course for primary health care workers in Ogun State, South West, Nigeria. Afr J Psychiatry 17: 141.

12. Ukpong D, Mosaku S (2009) Demographic and clinical correlates of length of stay in a Nigerian university hospital psychiatric unit. Turkish J psychiatry 20: 49-55.

13. Adamson TA, Onifade PO, Ogunwale A (2010) Trends in sociodemographic and drug abuse variables in patients with alcohol and drug use disorders in a Nigerian treatment facility. West Afr J Med 29: 12-18.

14. Masters GA, Baldessarini RJ, Öngür D, Centorrino F (2014) Factors associated with length of psychiatric hospitalization. Compr Psychiatry 55: 681-687.

15. Mai FM, Gosselin JY, Varan L, Bourgon L, Navarro JR (1993) Effects of treatment and alternative care on length of stay on a general hospital psychiatric unit-results of an audit. Can J Psychiatry 38: 39-45.

16. Stephens RJ, White SE, Cudnik M, Patterson ES (2014) Factors associated with longer length of stay for mental health emergency department patients. J Emerg Med 47: 412-419.

17. Zhang J, Harvey C, Andrew C (2011) Factors Associated with Length of Stay and the Risk of Readmission in an Acute Psychiatric Inpatient Facility: A Retrospective Study. Aust New Zeal J Psychiatry 45: 578-585.

18. McLay RN, Daylo A, Hammer PS (2005) Predictors of length of stay in a psychiatric ward serving active duty military and civilian patients. Mil Med 170: 219-222.

19. Stahl SM (2013) Essential Psychopharmacology: neuroscientific basis and practical applications. Cambridge university press 3: 943-1011.

20. Flaherty AW, Rost NS (2011) Kaplan and Sadock's synopsis of Psychiatry: Behavioral Sciences/Clinical Psychiatry. Wolters Kluwer Health 5: 1123-1175. 